PDFlib PLOP: PDF Linearization, Optimization, Protection

Page inserted by evaluation version www.pdflib.com - sales@pdflib.com 


\title{
Insulin-like Growth Factor Binding Protein Expression in SH-SY5Y Neuroblastoma Cells
}

\author{
EVA L. FELDMAN, ANN RANDOLPH, \\ AND DOUGLAS YEE ${ }^{a}$ \\ University of Michigan Medical Center \\ Ann Arbor, Michigan 48109 \\ ${ }^{a}$ University of Texas Health Science Center \\ San Antonio, Texas 78284
}

The insulin-like growth factors (IGF-I and IGF-II) are a family of proteins with both growth-promoting and insulin-like activity. Several lines of evidence indicate IGFs may serve as autocrine growth factors in the developing nervous system. IGF transcripts are abundant in human fetal brain, ${ }^{1}$ and in vitro, IGFs stimulate DNA synthesis and proliferation of cultured fetal neuroblasts. ${ }^{2}$ The actions of the IGFs are influenced by a family of high affinity binding proteins, designated IGFBPs. ${ }^{1}$ IGFBPs can modulate both the binding of IGFs to the type I and II IGF receptors and the distribution of IGFs among tissue compartments. ${ }^{1}$ In the current study, we examined gene and protein expression of IGFBPs in a well-characterized model system of neuronal growth, cultured human SH-SY5Y neuroblastoma cells. ${ }^{3}$ These cells, which express IGF-II and the type I and II IGF receptors, provide a good in vitro model for studying potential neuronal IGF-IGFBP interactions.

SH-SY5Y cells were cultured, as previously described, in the absence and presence of serum. ${ }^{3}$ Total RNA was analyzed by RNase protection. ${ }^{3}$ cDNA clones were obtained from Dr. S. Shimasaki (IGFBP-2, 4, 5, 6) and Dr. D. Powell (IGFBP1,3 ). Protected fragments were quantitated using a radioanalytic scanner (Ambis, San Diego, Calif.). Conditioned medium from SH-SY5Y cells, grown under serumfree conditions, was analyzed by western ligand blotting. ${ }^{4}$

RNase protection assays revealed four protected fragments corresponding to IGFBP-2 through IGFBP-5 (FIGURE 1). There was no detectable IGFBP-1 or 6 . The major transcript present was IGFBP-2 with approximately fourfold less expression of IGFBP-4 and barely detectable amounts of IGFBP-3 and 5. This pattern of gene expression parallels previously reported patterns in cerebrospinal fluid, brain, and cultured neural lines. ${ }^{5}$ Using western ligand blotting, SH-SY5Y cells secreted four IGFBPs with $M_{\mathrm{r}}$ estimates of $24,000,30,000,34,000$, and 46,000 (FIGURE 2). The major secreted forms were the 34,000 and the 24,000 forms, which likely corresponded to IGFBP-2 and IGFBP-4, respectively. A similar IGFBP secretion profile has been reported in other neural cell lines. ${ }^{5}$

In summary, human SH-SY5Y cells secreted four IGFBPs with $M_{\mathrm{r}}$ estimates of $24,000,30,000,34,000$, and 46,000. The major secreted forms, with $M_{\mathrm{r}}$ estimates of 34,000 and 24,000 , likely represented IGFBP-2 and IGFBP-4, respectively. Gene expression, determined by RNase protection assays, reflected protein secretion. The two major transcripts present were IGFBP-2 and IGFBP-4, with lesser amounts of IGFBP-3 and 5. Neither IGFBP-1 nor IGFBP-6 was detected by ligand blotting or RNase protection. As an initial step towards understanding the role of IGFBPs in 


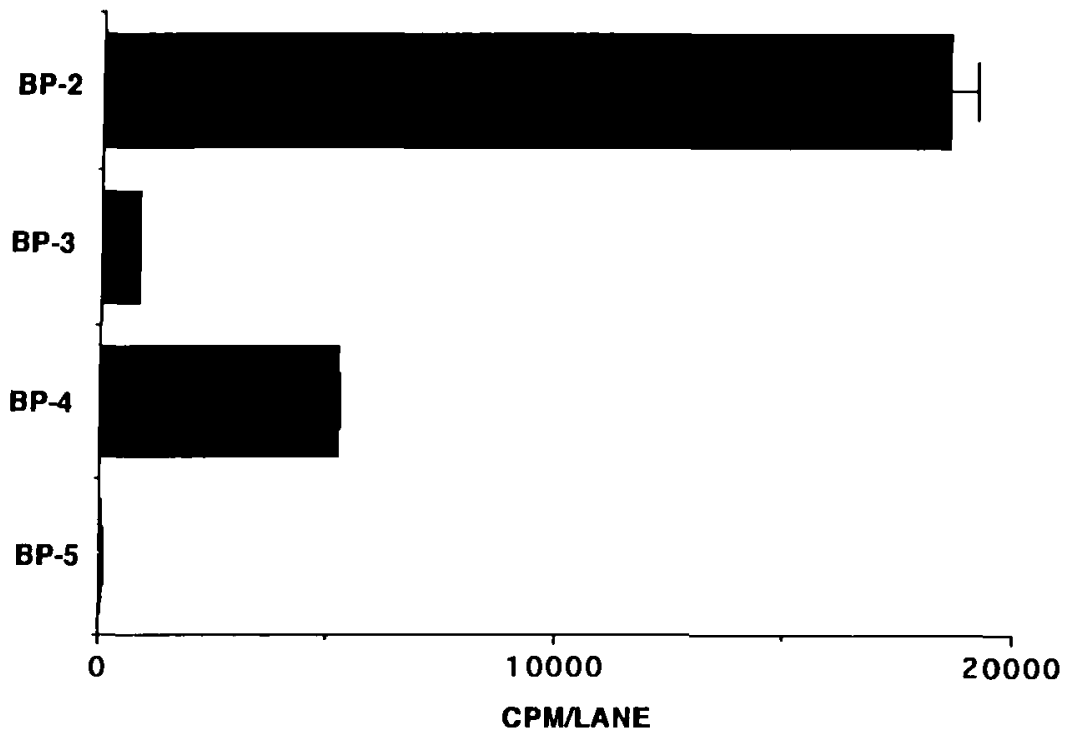

FIGURE 1. Radioanalytic scanner counts of IGFBP RNase protection assay of cultured SH-SY5Y neuroblastoma cells. The cRNA probes used to detect IGFBP mRNA were transcribed from different portions of the cDNAs. Protected fragments were quantitated by radioanalytic scanning.

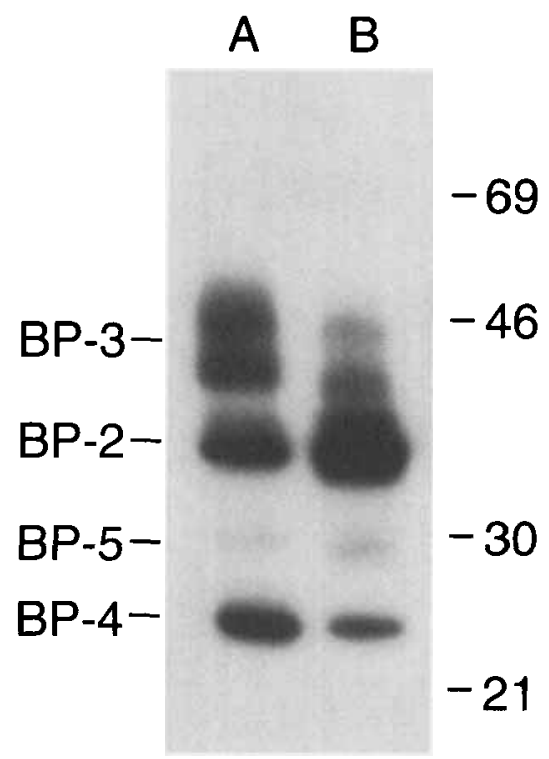

FIGURE 2. Ligand blot analysis of SH-SY5Y conditioned medium (CM). CM from either control ovarian carcinoma cells (lane A) or SH-SY5Y neuroblastoma cells was concentrated 20 -fold and electrophoresed through a $10 \%$ sodium dodecyl sulfate-polyacrylamide gel under nonreducing conditions. Proteins were electroblotted onto a nitrocellulose membrane and exposed to ${ }^{125} \mathrm{I}$-IGF-II. Tentative identification of IGFBPs was made based on $M_{\mathrm{r}}$ estimates. 
neuronal ontogeny, we have begun examining changes in IGFBP gene and protein expression during neuronal differentiation. ${ }^{6}$

\section{REFERENCES}

1. Sara, V. R., K. Hall, M. Misaki, L. Fryklund, N. Christensen \& L. Wetterberg. 1990. Insulin-like growth factors and their binding proteins. Physiol. Rev. 70: 591-614.

2. DiCicCo-BLOOM, E. \& I. B. BLACK. 1988. Insulin growth factors regulate the mitotic cycle in cultured rat sympathetic neuroblasts. Proc. Natl. Acad. Sci. USA 85: 4066-4070.

3. Martin, D. M., D. Yee, R. O. Carlson \& E. L. Feldman. 1992. Gene expression of the insulin-like growth factors and their receptors in human neuroblastoma cell lines. Mol. Brain Res. 15: 241-246.

4. COHICK, W. S. \& D. R. Clemmons. 1991. Regulation of insulin-like growth factor binding protein synthesis and secretion in a bovine epithelial cell line. Endocrinology 129: 13471354.

5. OCRANT, I. 1991. Insulin-like growth factor binding proteins in the nervous system. In Molecular Biology and Physiology of Insulin and Insulin-Like Growth Factors. M. K. Raizada \& Derek LeRoith, Eds. 293: 471-482. Plenum Press. New York, N.Y.

6. Feldman, E. L., A. Randol.PH, D. YeE \& D. M. Martin. 1992. Regulation of insulin-like growth factor binding protein gene expression in cultured neurons. Abstract 1166, page 343, The Endocrine Society 74th Annual Meeting, San Antonio, Texas. 